1044

\section{THE NUTRITIONAL PROFILE OF CHILDREN ADMITTED IN A DIGESTIVE ENDOSCOPY UNIT: A 3-YEAR STUDY}

V. Hurduc ${ }^{1}$, D. Plesca², M. Stefanescu², A. Zamfirescu², L. Bordei ${ }^{2}$

${ }^{1}$ Paediatric Gastroenterology, ${ }^{2}$ Paediatrics, Victor Gomoiu Childrens' Hospital, Carol Davila University of Medicine and Pharmacy, Bucharest, Romania

Background and aims: Nowadays numerous studies demonstrate unexpected modifications of nutritional deficiencies in children. This study aimed at determining the nutritional profile in symptomatic children submitted for the first upper endoscopy (EGD) in our unit during the last 3 years (2007 2009).

Methods: We conducted a retrospective study of 232 consecutive symptomatic children (149 girls, age range 2-18 years). Socioeconomic status, dietary and clinical data were analyzed. Weight, height, body mass index (BMI) for age and sex were recorded according to growth charts (CDC, 2000). H pylori was confirmed by urease test and histological examination.

Results: The nutritional status of the patients had the following repartition: 60 children $(25,86 \%)$ were underweight (BMI less than 5th percentile), 130 $(56,03 \%)$ had healthy weight, $27(11,63 \%)$ were at risk of becoming overweight and 15 children $(6,46 \%)$ were overweight (BMI greater than the 95th percentile). Of the 232 patients, $166(71,55 \%)$ had documented $\mathrm{H}$ pylori infection. This was inversely correlated with socioeconomic status $(p<0,005)$ and was mostly associated with normal nutritional status $(57,22 \%)$ compared with undernutrition and overnutrition (19,87\% and $22,89 \%$, respectively).

Conclusions: This endoscopic series shows a high prevalence rate of both undernutrition $(26,86 \%)$ and overnutrition $(18,09 \%)$ in children with abdominal complaints. Unexpectedly, the overnutrition was observed in a higher proportion in $\mathrm{H}$ pylori infected children.
1045

\section{EFFECT OF FOOD HABITS ON THE NUTRITIONAL AND ANTHROPOMETRIC PARAMETERS AMONG 250 ADOLESCENTS IN DJILLALI LIABES UNIVERSITY}

M.B. Khaled, B. Bahamida, F.Z. Bahamida

Biology, Djillali Liabes University of Sidi-Bel-Abbes, Sidi-Bel-Abbès, Algeria

According to the $\mathrm{WHO}$, one in every five people in the world is an adolescent, and $85 \%$ of them live in developing countries. Many boys and girls enter adolescence are malnourished can expose them later, to many complications and especially to chronic diseases. The importance of this period of life, when the growth reaches its maximum, it led us to assess the nutritional status of a group of adolescents and focus on their daily nutritional intake.

The aim of our study, which took place at the "Djilali Liabès University" exactly in Sidi-Bel-Abbès City, on 250 healthy adolescents (49.6\% girls and $50.4 \%$ boys) aged between 17 and 22 years old, was to discuss the impact of eating habits change of adolescent.

During our enquiry, anthropometric data, questionnaires, and the 24 hours dietary recall were used and collected on all the adolescents to evaluate the dietary habits. The USDA's nutrient database was used for our Nutrinux ${ }^{\circledR}$ program in order to perform the nutrient accounts.

Results showed that the overweight among boys is more important than girls $(p<0.0001)$ because $69 \%$ of girls skip a meal to control their weight. An excess in sugars was noticed among girls, and fats were overtaken by boys. However, the protein consumption agreed with nutritional recommendations. A calcium deficiency was found which can probably present a risk for our girls later.

Finally, the eating habits change of adolescents has a great impact and many serious consequences that can affect their health in short and long term. 